\title{
Влияние структуры кремнезема на процесс его дегидратации
}

\author{
Нефедова T.H. ${ }^{1,2}$, Thomé A.G. ${ }^{1}$, Schroeter F. ${ }^{1}$, \\ Селеменев В.Ф. ${ }^{3}$, Roessner F. ${ }^{1}$ \\ ${ }^{1}$ Ольденбургский университет имени Карла фон Осецякого, Ольденбург, Германия \\ ${ }^{2}$ Воронежский государственный технический университет, Воронеж \\ ${ }^{3}$ ФБГОУ ВО «Воронежский государственный университет», Воронеж
}

Поступила в редакцию 12.10.2017 г.

Методом ИК-спектроскопии диффузного отражения в режиме «іn situ» исследовано влияние структуры модификаций кремнезема - MCM-41 (мезопористый, высокоупорядоченный), SBA-15 (микро-мезопористый, высокоупорядоченный), Н-магадиита (слоистый), силикалита (микропористый) и силикагеля (аморфный, пористый) - на процесс их дегидратации. Установлено, что дегидратация исследуемых разновидностей диоксида кремния включает десорбцию физически связанной воды, распад связанных водородной связью силанольных групп и их дегидроксилирование. Закономерность процесса не зависит от структурных особенностей модификаций кремнезема, разница наблюдается только в температурных диапазонах стадий дегидратации.

Ключевые слова: дегидратация, кремнезем, MCM-41, SBA-15, Н-магадиит, силикалит, силикагель, ИК-спектроскопия диффузного отражения.

\section{Influence of silica structure on its dehydration}

\author{
Nefedova T.N. ${ }^{1,2}$, Thomé A.G. ${ }^{1}$, Schroeter F. ${ }^{1}$, Selemenev V.F. ${ }^{3}$, Roessner F. ${ }^{1}$ \\ ${ }^{1}$ Carl von Ossietzky University, Oldenburg, Germany \\ ${ }^{2}$ Voronezh State Technical University, Voronezh \\ ${ }^{3}$ Voronezh State University, Voronezh
}

The influence of structure of the different silica modifications - MCM-41 (ordered mesoporous), SBA-15 (ordered micro-mesoporous), H-magadiite (layered), silicalite (microporous) and silica gel (amorphous, porous) - on their dehydration was studied by «in situ» DRIFT- spectroscopy under heating of samples. The textural properties of the samples were obtained by means of $\mathrm{N}_{2}$ - physisorption. The pore volume and pore diameter were calculated by the BJH method. The surface area was determined in according to BET.

Several species on the silica surface were identified: hydrogen bonded vicinal and terminal silanol groups. Their interaction with water molecules results in the broad band of OH-stretching vibration poor resolved in dependence on the studied samples. Noteworthy, that in case of layered H-magadiite hydroxyl groups located in the interlayer space were identified. Their strong interaction results in a shrinking of the basal distance between the layers as detected by measuring the accessible surface using BET. It is also reflected in the high intensity of $\mathrm{OH}$-stretching vibration of hydrogen bonded silanol groups.

It was established, that the dehydration of the different forms of silica includes three stages: (i) desorption of physisorbed water, (ii) decomposition of hydrogen bonded silanol groups accompanied by the increase of intensity of the free silanol groups $\left(3740 \mathrm{~cm}^{-1}\right)$ and (iii) their dehydroxylation. Principle of the dehydration process does not depend on the structural features of the investigated silica modifications but it differs only in the temperature ranges of the dehydration stages.

Keywords: dehydration, silica, MCM-41, SBA-15, H-magadiite, silicalite, silica gel, DRIFT- spectroscopy.

Нефедова и др. / Сорбционные и хроматографические процессы. 2017. Т. 17. № 5 


\section{Введение}

Кремнезем или диоксид кремния является основой многих минералов, встречающихся в природе, и может быть, как природного, так и синтетического происхождения. Кремнезем и его модификации широко применяются в промышленности, в реакциях гетерогенного катализа, препаративной и аналитической хроматографии [1-7]. Структура, свойства и состав материалов определяет направление и результативность их использования.

Согласно литературным данным [8-13] поверхность кремнезема характеризуется присутствием силоксановых и силанольных групп. Однако, благодаря подвижности протона силанольной группы, способного вступать в реакции обмена, наиболее реакционноспособным считается именно этот тип групп [8-13]. Различают сингулярные, геминальные и водородно-связанные силанольные группы, которые, в свою очередь, подразделяются на водородно-связанные силанольные группы с внутримолекулярной связью или вицинальные (ОН-группы, связанные между собой водородной связью) и водородно-связанные силанольные группы с межмолекулярной водородной связью (ОН-группы, имеющие связи с молекулами воды) [8-13]. В зависимости от структуры диоксида кремния количество и соотношение видов ОН-групп может изменяться $[9,11]$.

Следует отметить, что помимо силанольных и силоксановых групп поверхность кремнезема может содержать и молекулы адсорбированных веществ, в частности, молекулы воды. Наличие молекул воды, как правило, снижает реакционную активность кремнезема. В настоящее время накоплен достаточно обширный материал, посвященный изучению гидратации различных форм диоксида кремния с помощью разнообразных методов исследования [14-17]. Основной целью данной работы было изучить влияние особенностей структуры модификаций кремнезема на процесс их дегидратации. Иными словами, установить взаимосвязь «структура материала процесс дегидратации».

\section{Эксперимент}

Объекты исследования. В работе были использованы следующие разновидности кремнезема: MCM-41, SBA-15, Н-магадиит, силикагель и силикалит, структурные характеристики которых представлены в таблице 1.

MCM-41 и SBA-15 являются высокоупорядоченным мезопористыми модификациями кремнезема с гексагональной двухмерной структурой пор, которые были синтезированы согласно методикам [18]. SBA-15 в своем строении помимо мезопор характеризуется присутствием небольшого количества микропор [19, 20].

Силикагель «Köstrosorb 1008» (CWK Bad Köstritz, Germany) - аморфный пористый диоксид кремния. Силикалит (Tricat Zeolites, Bitterfeld, Germany) - диоксид кремния, имеющий структуру, подобную цеолитам пентасильного типа. Основным структурным элементом силикалита является фрагмент из пяти- и шестичленных колец. Фрагменты сочетаются цепочки, образующие слои и каналы разного типа: размер каналов не превышает более 0.55 нм [11].

Н-магадиит - кремнезем слоистой структуры, который представляет собой модифицированную с помощью ионного обмена форму Na-Магадиита (синтезирован Pr. Schwieger, University of Nuremberg - Erlangen, Germany). Модификация NaМагадиита осуществлялась согласно реакции:

$$
\equiv \mathrm{SiON} a+\mathrm{HCl} \leftrightarrow \equiv \mathrm{SiO} H+\mathrm{NaCl},
$$

где $\equiv \mathrm{SiONa}-\mathrm{Na-магадиит;} \equiv \mathrm{SiOH}-\mathrm{H}$-магадиит. 


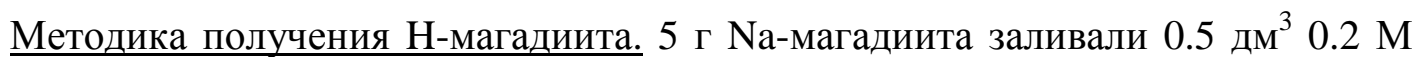
раствором соляной кислоты и выдерживали при комнатной температуре в течении 6 часов. Далее образец переносили на фильтр и отмывали от избытка $\mathrm{HCl}$ дистиллированной водой до отрицательной реакции в промывных водах на хлорид-ионы (реакция с нитратом серебра). Полученный Н-магадиит высушивали в сушильном шкафу в течение 2 суток при температуре $50^{\circ} \mathrm{C}$.

Структурные характеристики образцов были получены с помощью метода низкотемпературной адсорбции азота на приборе ASAP- 2060 (Micromeritics, USA). Площадь поверхности рассчитывалась по методу БЭТ, объем и диаметр пор - по методу ВЈН.

Таблица 1. Структурные характеристики модификаций кремнезема: SBA-15, силикагеля, МСМ-41, силикалита и Н-магадиита.

\begin{tabular}{|c|c|c|c|c|c|}
\hline $\begin{array}{c}\text { Модификация } \\
\text { кремнезема }\end{array}$ & Структура & $\begin{array}{c}\mathrm{S}_{\text {Бэт, }} \\
\mathrm{m}^{2} / \Gamma\end{array}$ & $\begin{array}{c}\mathrm{V} \text { пор } \\
\mathrm{cm}^{3} / \Gamma\end{array}$ & $\begin{array}{c}\mathrm{d} \text { пор, } \\
\mathrm{HM}\end{array}$ & $\begin{array}{c}\mathrm{V} \text { микро- } \\
\text { пор, см } 3 / \Gamma\end{array}$ \\
\hline SВА-15 & $\begin{array}{c}\text { микро-мезопористая, } \\
\text { высокоупорядоченная }\end{array}$ & 805 & 1.43 & 8.0 & - \\
\hline Силикагель & пористая & 267 & 0.95 & 12.06 & - \\
\hline МСМ-41 & $\begin{array}{c}\text { мезопористая, высоко- } \\
\text { упорядоченная }\end{array}$ & 1015 & 0.77 & 3.4 & - \\
\hline Силикалит & микропористая & 396 & 0.2 & - & 0.11 \\
\hline Н-магадиит & слоистая & 39 & - & - & - \\
\hline
\end{tabular}

Метод исследования дегидратации. Дегидратация модификаций кремнезема исследовалась с помощью метода ИК-спектроскопии диффузного отражения в режиме «in situ» в процессе непрерывного нагревания образцов до достижения определенных температур. Измерения проводились на спектрометре «IRAffinity 1s» (Shimadzu, Japan), оснащенном специализированной для такого рода измерений ячейкой «Praying Mantis ${ }^{\mathrm{TM}}$ », в токе и без тока азота. Скорость тока азота составляла $90 \mathrm{~cm}^{3} /$ мин. Каждый образец при заданной температуре выдерживался не менее 7 минут. Температурный режим задавался и поддерживался с помощью термоконтроллера «Jumo dTRON 316». Скорость нагрева образцов - $5^{\circ} \mathrm{C} /$ мин. Пробы анализировали в виде порошка, предварительно разбавляя их бромидом калия в соотношении 1:20.

\section{Обсуждение результатов}

Полученные ИК-спектры силикагеля (рис.1), MCM-41 (рис. 2), SBA-15 (рис. 3), силикалита (рис. 4) и Н-магадиита (рис. 5) без применения в процессе измерения тока азота демонстрируют исходное гидратированное состояние исследуемых материалов.

На ИК-спектрах силикагеля (рис. 1), кремнезема с пористой неупорядоченной структурой, при непрерывном нагревании образца до температуры $140^{\circ} \mathrm{C}$ отмечается снижение интенсивности полосы деформационных колебаний физически адсорбированной воды при $1627 \mathrm{~cm}^{-1}$, а также интенсивности широкой полосы и плеча в диапазоне от 3363-3662 см$^{-1}$, которые отвечают за валентные колебания ОН-связей водородно-связанных силанольных групп [9,11]. Наблюдаемое, вероятнее всего, указывает на ослабление и далее на постепенный полный разрыв водородных связей между силанольными группами, связанными с молекулами воды (снижение интенсивности полос при 3363 и $3662 \mathrm{~cm}^{-1}$ ), о чем свидетельствует увеличение интенсивности полосы валентных колебаний сингулярных силанольных групп (полоса 
$3740 \mathrm{~cm}^{-1}$ ). Всё это приводит к выводу о протекании десорбции физически связанной воды с поверхности образца.

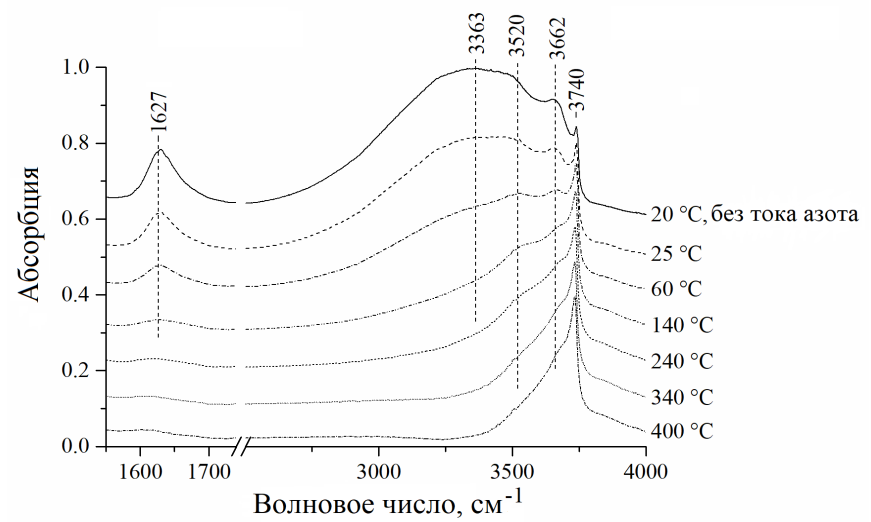

Рис. 1. ИК-спектры диффузного отражения силикагеля в режиме «in situ» при $20^{\circ} \mathrm{C}$ (без тока азота), $25,60,140,240,340$ и $400^{\circ} \mathrm{C}$ (в токе азота).

Следует учесть, что поверхность силикагеля также может содержать и силанольные группы с внутримолекулярной водородной связью (вицинальные), на присутствие которых указывает полоса при $3520 \mathrm{~cm}^{-1}[9,11]$, наиболее ярко проявляющаяся при температуре $60^{\circ} \mathrm{C}$ после удаления значительной части объема физически адсорбированной воды. В процессе нагревания образца от 60 до $140^{\circ} \mathrm{C}$ интенсивность её колебаний снижается, что свидетельствует об ослаблении водородных связей между вицинальными силанольными группами, которое, в отличие от ситуации с силанольными группами, имеющими связи с молекулами воды, сопровождается лишь частичным разрывом связи и постепенным переходом их (групп) к более свободному состоянию [11], внося тем самым вклад в возрастание интенсивности полосы валентных колебаний свободных (сингулярных) силанольных групп. При нагреве силикагеля от 140 до $400{ }^{\circ} \mathrm{C}$ происходит дальнейшее снижение интенсивности полосы валентных колебаний ОН-связей вицинальных силанольных групп и совсем незначительное увеличением интенсивности полосы валентных колебаний изолированных ОН-групп. Из чего следует, очевидно, что на данном этапе продолжается распад связанных внутримолекулярной водородной связью силанольных групп с преобразованием их в более свободное состояние, а обезвоживание образца осуществляется за счёт процесса дегидроксилирования (конденсации силанольных групп).

Необходимо отметить, что четко разграничить этапы дегидратации кремнезема, в частности силикагеля, очень сложно, так как они могут проходить одновременно, и удается только выделить наиболее превалирующий в конкретном интервале температур $[9,13]$.

Для высокоупорядоченного мезопористого MCM-41 (рис. 2) наблюдается аналогичное протекание процесса дегидратации, что и для аморфного мезопористого силикагеля. Единственное отличие для МСМ-41 заключается в том, что, скорее всего, бо́льшая часть физически связанной воды (рис. 2) десорбируется в интервале температур $25-60^{\circ} \mathrm{C}$. В пользу данного предположения свидетельствует заметное снижение интенсивности полосы деформационных колебаний физически адсорбированной воды $\left(1627 \mathrm{~cm}^{-1}\right)$ и интенсивности полос валентных колебаний $\mathrm{OH}$-связей силанольных групп, связанных с молекулами воды (3415 и $3682 \mathrm{~cm}^{-1}$ ) в указанном диапазоне температур. Данное отличие, по- видимому, обусловлено высокой упорядоченностью структуры мезопористого МСМ-41 и его достаточно узким распределением пор по размеру, что, в свою очередь, может облегчать процесс удаления молекул воды с поверхности кремнезема (МСM-41) по сравнению с силикагелем, у ко- 
торого кремний кислородные тетраэдры расположены нерегулярно и образуют поры с широким разбросом по размеру [9,11]. Наличие микропор пор (с положительным радиусом кривизны) в структуре кремнезема способствует расширению температурного интервала десорбции физически связанной воды [13], что и наблюдается при обезвоживании силикагеля.

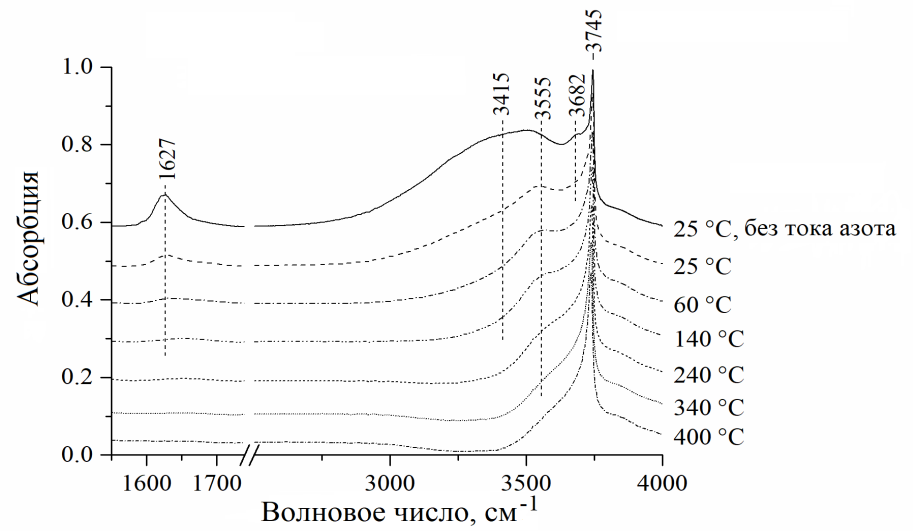

Рис. 2. ИК-спектры диффузного отражения МСM-41 в режиме «in situ» при $25^{\circ} \mathrm{C}$ (без тока азота), 25, 60, 140, 240, 340 и $400{ }^{\circ} \mathrm{C}$ (в токе азота).

В случае высоко упорядоченного микро-мезопористого SBA-15 (рис. 3) дегидратация осуществляется по тому же принципу, что и обезвоживание силикагеля, но с учетом особенностей этого процесса для МСМ-41, т.е. больша́я часть физически адсорбированной воды удаляется от 25 до $60^{\circ} \mathrm{C}$.

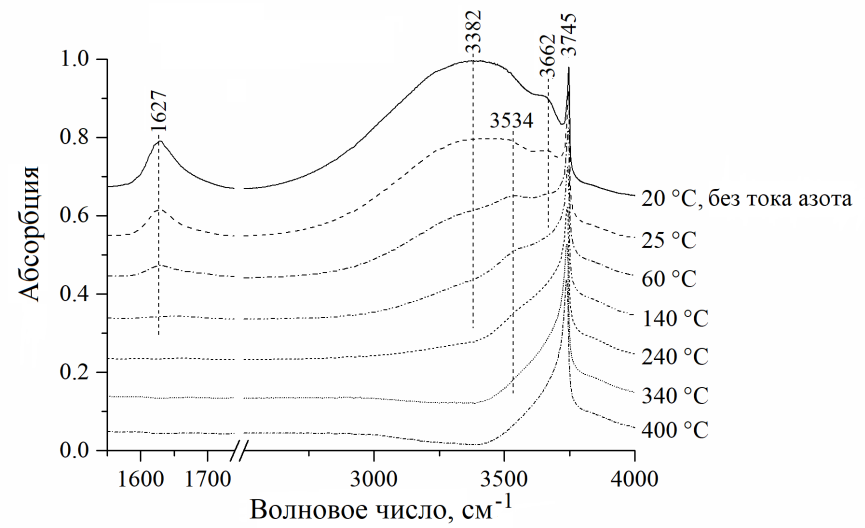

Рис. 3. ИК-спектры диффузного отражения SBA-15 в режиме «in situ» при $20^{\circ} \mathrm{C}$ (без тока азота), $25,60,140,240,340$ и $400^{\circ} \mathrm{C}$ (в токе азота).

Наличие микропор в структуре SBA-15 делает его подобным силикагелю, а регулярность строения и мезопоры - МСМ-41. В отличие от МСМ-41 снижение интенсивности полосы деформационных колебаний воды $\left(1627 \mathrm{~cm}^{-1}\right)$ и интенсивности полос колебаний ОН-связей силанольных групп, имеющих связи с молекулами воды (3382 и $3662 \mathrm{~cm}^{-1}$ ) у SBA-15 выражено в меньшей степени для интервала температур от 25 до $60^{\circ} \mathrm{C}$, что как раз, вероятнее всего, обусловлено влиянием присутствия микропор в его структуре, способных сильнее удерживать молекулы воды [13].

Закономерность процесса обезвоживания силикалита (рис. 4) также не сильно отличается от закономерности процесса обезвоживания силикагеля, MCM-41 и SBA15. Однако, необходимо отметить, в силу того, что связи Si-O-Si в его структуре в высокой степени насыщены данная модификация кремнезема практически гидрофобна [11]. Немногочисленные силанольные группы могут появляться на поверхности силикалита, скорее всего, в основном за счет возникающих структурных дефек- 
тов, вследствие чего, интенсивность полос валентных колебаний ОН-связей водородно-связанных $\left(3432,3528,3657 \mathrm{~cm}^{-1}\right)$ и свободных силанольных групп $\left(3738 \mathrm{~cm}^{-1}\right)$ на его ИК-спектрах выражена очень слабо.

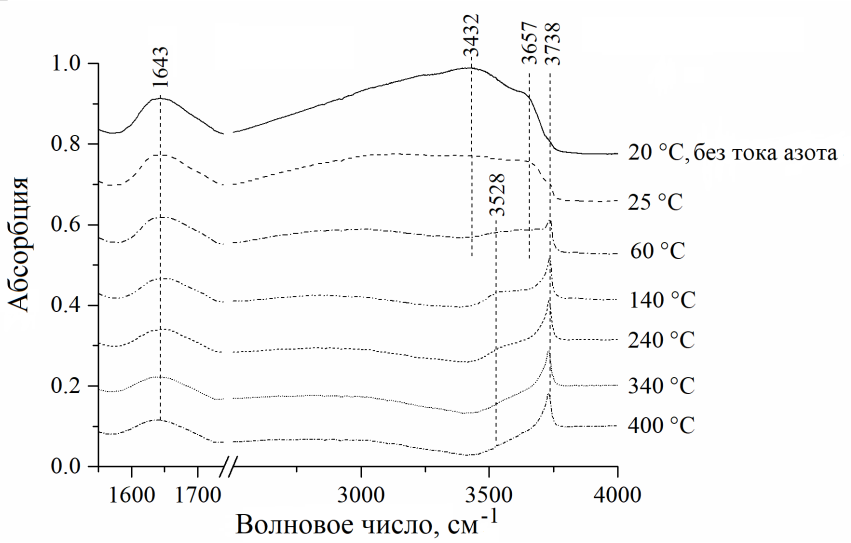

Рис. 4. ИК-спектры диффузного отражения силикалита в режиме «in situ» при $20^{\circ} \mathrm{C}$ (без тока азота), $25,60,140,240,340$ и $400^{\circ} \mathrm{C}$ (в токе азота).

Полоса при $3528 \mathrm{~cm}^{-1}$, которая предположительно, отвечает за валентные колебания ОН-связей вицинальных силанольных групп, проявляется наиболее отчетливо только при температуре $140^{\circ} \mathrm{C}$ (после десорбрции значительной части объема физически связанной воды), а не при $60^{\circ} \mathrm{C}$, как у силикагеля. Возможной причиной этому может служить микропористость структуры данной разновидности кремнезема. Как отмечалось ранее, чем меньше диаметр пор, тем сильнее удерживается физически адсорбированная вода в этих порах $[9,13]$. В свою очередь, наблюдаемая высокая интенсивность полосы деформационных колебаний физически адсорбированной воды (1643 см $\left.{ }^{-1}\right)$ объясняется её перекрыванием с полосами поглощения обертона и составных тонов колебаний кремнеземной матрицы $[9,11]$.

ИК-спектр Н-магадиита (рис. 5), кремнезема слоистой структуры, характеризуется бо́льшим набором полос колебаний ОН-связей водородно-связанных силанольных групп и бо́льшей их интенсивностью в диапазоне 3199-3718 см-1 по сравнению с выше рассмотренными модификациями кремнезема. Вероятнее всего, это связано со спецификой его структуры, а именно, поверхностные свободные силанольные группы, относящиеся к разным слоям Н-магадиита, в межслоевом пространстве находятся на достаточно близком расстоянии друг к другу, что приводит к возникновению водородных связей между ними и сокращению их числа (очень слабая интенсивность полосы при $3746 \mathrm{~cm}^{-1}$ ), а, возможно, и межслоегого расстояния (низкое значение площади поверхности (см. табл. 1).

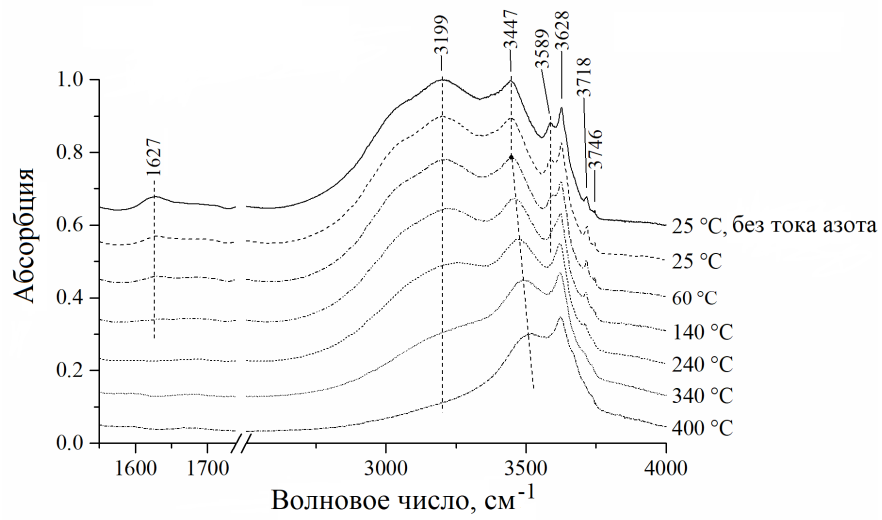

Рис. 5. ИК-спектры диффузного отражения Н-магадиита в режиме «in situ» при $25{ }^{\circ} \mathrm{C}$ (без тока азота), 25, 60, 140, 240, 340 и $400^{\circ} \mathrm{C}$ (в токе азота). 
В итоге в структуре кремнезема начинают преобладать вицинальные силанольные группы над свободными силанольными группами и силанольными группами, связанными с молекулами воды (слабая интенсивность полосы при $3589 \mathrm{~cm}^{-1}$ ), сообщая Н-магадииту гидрофобные свойства - очень низкая интенсивность полосы деформационных колебаний воды $\left(1627 \mathrm{~cm}^{-1}\right)$ и валентых колебаний ОН-связей силанольных групп, связанных с молекулами воды. Не смотря на все особенности в структуре Н-магадиита, процесс его дегидратации не нарушает общей закономерности и совпадает с остальными разновидностями кремнезема с единственным наблюдаемым отличием: снижение на ИК-спектрах, полученных при разных температурах, интенсивности полосы валентных колебаний свободных силанольных групп до полного её исчезновения. Возможно, это происходит из-за того, что при нагревании образца, в результате удаления физически адсорбированной воды, силанольные группы, связанные с молекулами воды, становятся свободными и далее взаимодействуют друг с другом с образованием вицинальных силанольных групп, чему также способствует малое расстояние между слоями Н-магадиита.

\section{Заключение}

Таким образом, было установлено, что дегидратация модификаций кремнезема - MCM-41 (мезопористый, высокоупорядоченный), SBA-15 (микромезопористый, высокоупорядоченный), Н-магадиита (слоистый), силикалита (микропористый) и силикагеля (аморфный, пористый) - включает десорбцию физически связанной воды, распад связанных водородной связью силанольных групп и их дегидроксилирование. Закономерность процесса не зависит от структурных особенностей модификаций кремнезема, разница наблюдается только в температурных диапазонах стадий дегидратации.

Aвторы выражают благодарность Prof. Dr. Schwieger, University of Nuremberg - Erlangen, Germany за предоставленные для исследования образцы синтезированного Na-Mагадиита.

Проект выполнен при финансовой поддержке Германской службы академических обменов (DAAD) в рамках программ «Михаил Ломоносов», «Научноисследовательские стипендии» и по проектам Министерства образования и науки РФ государственного заказа No.11.7137.2013, 4.10002.2017/5.2.

\section{Список литературы}

1. Weitkamp J., Weiß Ul., Ernst St. Catalysis by Microporous Materials. Amsterdam. Elsevier Science. 1995. Vol. 94, pp. 363-380.

2. Armor John N. // Applied Catalysis B: Environmental. 1992. Vol. 1. Iss. 4. pp. 221-256.

3. Walcarius A., Mercier L. // J. Mater. Chem. 2010. Vol. 20. Iss. 22. pp. 4478-4511.

4. Perego C., Bosetti A. // Microporous Mesoporous Mater. 2011. Vol. 144. pp. 28-39.

5. Ishizuka N., Nakanishi K., Hirao K., Tanaka N. // Journal of Sol-Gel Science and Technology. 2000. Vol. 19. pp. 371-375.
6. Diliberto Joseph J. // Journal of Pharmaceutical Sciences. 1969. Vol. 58. Iss. 6. pp. 747749.

7. Schiel John E., Mallik R., Soman S., Joseph K.S.et al. // J. Sep. Sci. 2006. Vol. 29. Iss. 6. pp. 719-737.

8. Чукин Г.Д. Химия поверхности и строение дисперсного кремнезёма. М. Паладин. ООО «Принта». 2008. 172 с.

9. Киселев А.В., Лыгин В.И. Инфракрасные спектры поверхностных соединений. М. Наука. 1972. 459 с. 
10.Баландин А.А. // «Поверхностные химические соединения и их роль в явлениях адсорбции», сборник трудов конференции по адсорбции, посвящ. 200-летию МГУ им. М. Ломоносова: 1755-1955 гг. М. 1957. С. 277.

11.Киселев А.В. Межмолекулярные взаимодействия в адсорбции и хроматографии. М. Высшая школа. 1986. 369 с.

12.Зайцев В.Н., Скопенко В.В. Комплексообразующие кремнеземы, синтез, строение привитого слоя и химия поверхности. Харьков. Фолио. 1997. 239 с.

13.Лисичкин Г.В., Фадеев А.Ю., Сердан А.А., Нестеренко П.Н. и др. Химия привитых поверхностных соединений. М. Физматлит. 2003. $111 \mathrm{c}$.

14.Langille K.B., Nguyen D., Bernt J.O., Veinot D.E. et al. // J. Mater. Sci. 1991. Vol. 26. Iss. 3. pp 704-710.

\section{References}

1. Weitkamp J., Weiß Ul., Ernst St. Catalysis by Microporous Materials. Amsterdam. Elsevier Science, 1995, Vol. 94, pp. 363-380.

2. Armor John N., Applied Catalysis B: Environmental, 1992, Vol. 1, Iss. 4, pp. 221-256. DOI:10.1016/0926-3373(92)80051-Z

3. Walcarius A., Mercier L., J. Mater. Chem., 2010, Vol. 20, Iss. 22, pp. 4478-4511. DOI: 10.1039/B924316J.

4. Perego C., Bosetti A., Microporous Mesoporous Mater., 2011, Vol. 144, pp. 28-39. DOI: 10.1016/j.micromeso.2010.11.034.

5. Ishizuka N., Nakanishi K., Hirao K., Tanaka N., Journal of Sol-Gel Science and Technology, 2000, Vol. 19, pp. 371-375. DOI: 10.1023/A:1008770707572.

6. Joseph J. Diliberto, Journal of Pharmaceutical Sciences, 1969, Vol. 58, Iss. 6, pp. 747749. DOI: $10.1002 /$ jps.2600580622.

7. Schiel John E., Mallik R., Soman S., Joseph K.S et al., J. Sep. Sci., 2006, Vol. 29, Iss. 6, pp. 719-737. DOI: 10.1002/jssc.200500501.

8. Chukin G.D. Khimiya poverhnosti i stroenie dispersnogo kremnezyoma, M., Paladin Pbl., OOO «Printa», 2008, 172 p.

9. Kiselev A.V., Lygin V.I. Infrakrasnye spektri poverhnostniyh soedinenij, M., Nauka Pbl., 1972, 459 p.

10. Balandin A.A. "Surface chemical compounds and its role in adsorption phenomena", Proceeding of the Adsorption Conference devoted to 200 anniversary of the MSU named M.
15.Iozzi Maria Fr., Bisio Ch., Regi-Macedo Th., Airoldi C. et al. // J. Mater. Chem. 2009. Vol. 19. pp. 2610-2617.

16.Shawa S., Henderson C.M.B., Komanschek B.U. // Chemical Geology. 2000. Vol. 167. Iss. 1-2. pp. 141-159.

17.Lawrence C. D. // Nature. 1964. Vol. 201. pp. 607-609.

18.Zhao H., Hu J., Wang J., Zhou L. et al. // Acta Phys. -Chim. Sin. 2007. Vol. 23. Iss. 6. pp. 801-806.

19.Hoang V-Th., Huang Q., Eić M., Do Tr.On et al. // Langmuir. 2005. Vol. 21. No 5. pp. 2051-2057.

20.Thielemann J.P., Girgsdies Fr., Schlögl R., Hess C. // Beilstein J. Nanotechnol. 2011. Vol. 2. pp. 110-118.

Lomonosov: 1755-1955 years. M., 1957, pp. 277.

11. Kiselev A.V. Mezhmolekulyarnie vzaimodeystviya $\mathrm{v}$ adsorbtsii i hromatografii. M., Visshaya shkola Pbl., 1986, 369 p.

12. Zajcev V.N., Skopenko V.V. Kompleksoobrazuyushchie kremnezemi, sintez, stroenie privitogo sloya i khimiya poverhnosti. Kharkiv, Folio Pbl., 1997, 239 p.

13. Lisichkin G.V., Fadeev A.Y., Serdan A.A., Nesterenko P.N. et al., Chemistry of Surface Grafted Compounds. M., Fizmatlit Pbl., 2003, 111 p.

14. Langille K.B., Nguyen D., Bernt J.O., Veinot D.E. et al., J. Mater. Sci., 1991, Vol. 26, Iss. 3, pp 704-710. DOI:10.1007/BF00588307.

15. Iozzi Maria Fr., Bisio Ch., Regi-Macedo Th., Airoldi C. et al., J. Mater. Chem., 2009, Vol. 19, pp. 2610-2617. DOI: 10.1039/B822013C.

16. Shawa S., Henderson C.M.B., Komanschek B.U., Chemical Geology, 2000, Vol. 167, Iss. 1-2, pp. 141-159. DOI:10.1016/S00092541(99)00206-5.

17. Lawrence C.D., Nature, 1964, Vol. 201, pp. 607-609. DOI:10.1038/201607b0.

18. Zhao H., Hu J., Wang J., Zhou L. et al., Acta Phys. -Chim. Sin., 2007, Vol. 23, Iss. 6, pp. 801-806. DOI: 10.1016/S1872-1508(07)600461.

\author{
.
}


19. Hoang V-Th., Huang Q., Eić M., Do Tr.On et al., Langmuir, 2005, Vol. 21, No 5, pp. 2051-2057. DOI: 10.1021/la048349d.

Нефедова Татьяна Николаевна - старший научный сотрудник НИЦ «Фундаментальные исследования в области естественных и строительных наук», Воронежский государственный технический университет, Воронеж

Томе Андреас Георг - аспирант кафедры технической химии 2, института химии, Ольденбургского университета имени Карла фон Осецкого, Ольденбург, Германия

Шретер Франк - магистрант кафедры технической химии 2, института химии, Ольденбургского университета имени Карла фон Осецкого, Ольденбург, Германия

Селеменев Владимир Федорович - профессор, зав. каф. аналитической химии, Воронежский государственный университет, Воронеж

Ресснер Франк - профессор, зав. каф. технической химии 2, института химии, Ольденбургского университета имени Карла фон Осецкого, Ольденбург, Германия
20. Thielemann J.P., Girgsdies Fr., Schlögl R., Hess C., Beilstein J. Nanotechnol., 2011, Vol. 2, pp. 110-118. DOI:10.3762/bjnano.2.13.

Nefedova Tatiana N. - senior researcher SRC "Fundamental research in the fields of natural and building science", Voronezh State Technical University, Voronezh, Russia; Postdoctoral Researcher at Department of Industrial Chemistry 2, Institute of Chemistry, Carl von Ossietzky University, Oldenburg, Germany, e-mail: TNephedova@gmail.com

Thomé Andreas Georg- PhD student, Department of Industrial Chemistry 2, Institute of Chemistry, Carl von Ossietzky University, Oldenburg, Germany, e-mail: andreas.georg.thome@uni-oldenburg.de

Schroeter Frank - M.sc. student, Department of Industrial Chemistry 2, Institute of Chemistry, Carl von Ossietzky University, Oldenburg, Germany, e-mail: frank.schroeter@uni-oldenburg.de

Selemenev Vladimir F.- professor, the head the department of Analytical Chemistry, faculty of Chemistry, Voronezh State University, Voronezh, Russia, e-mail: common@chem.vsu.ru

Roessner Frank - professor, head of the Department of Industrial Chemistry 2, Institute of Chemistry, Carl von Ossietzky University, Oldenburg, Germany; e-mail: frank.roessner@unioldenburg.de 